\title{
A gestão estratégica de custos como instrumento para redução do trade-off entre custo e diferenciação baseada na flexibilidade
}

\author{
César Volnei Mauss \\ Mestrado em Ciências Contábeis pela Universidade do Vale do Rio dos Sinos - \\ UNISINOS \\ Professor da Universidade Luterana do Brasil - Campus Carazinho \\ E-mail: cezarvolnei@yahoo.com.br
}

Juliano Machado de Magalhães Mestrado em Administração pela Universidade do Vale do Rio dos Sinos - UNISINOS Professor do Centro Universitário Leonardo da Vinci - UNIASSELVI E-mail: julianommagalhães@gmail.com

Marcos Antonio de Souza Doutorado em Controladoria e Contabilidade pela Universidade de São Paulo - USP Professor da Universidade do Vale do Rio dos Sinos - UNISINOS E-mail:marcosas@unisinos.br

\section{RESUMO}

O objetivo desta pesquisa foi investigar como a gestão estratégica de custos poderia atuar para reduzir os custos da adoção de uma estratégia baseada em sistemas customizados. O enfoque metodológico adotado foi o estudo de caso único, desenvolvido em uma empresa do segmento moveleiro. A empresa modificou sua estratégia de produção, anteriormente focada em móveis padronizados, para a produção customizada em massa. A coleta de dados deu-se pela análise documental e por meio de entrevistas semi-estruturadas realizadas com os gestores da empresa. Como conclusão, identificou-se que o trade-off inicial existente entre custos e flexibilidade foi parcialmente reduzido com a utilização de técnicas de gestão estratégica de custos, as quais induziram mudanças no processo produtivo. Tal redução só não foi mais acentuada tendo em vista as ainda limitadas possibilidades da empresa melhor explorar as relações de sua cadeia de valor.

Palavras-chave: Gestão estratégica de custos. Critérios competitivos. Trade-off.

Cost strategic management as an instrument to reduce trade-off between cost and differentiation based on flexibility 
A gestão estratégica de custos como instrumento para redução do trade-off entre custo e
diferenciação baseada na flexibilidade César Volnei Mauss, Juliano Machado de Magalhães, Marcos Antonio de Souza

\section{ABSTRACT}

The goal of this research was to investigate how cost strategic management can help to reduce costs resulting from the strategy based on customized systems. The methodological focus used was the single case study, developed in a furniture company. This company changed its production strategy, previously focused on standardized furniture, for customized mass production. The data mining process included documents analyses and semi-structured interviews performed with the company's managers. As a conclusion we identified that the initial existing trade-off between costs and flexibility was partially reduced by the use of cost strategic management techniques, which led to changes in the productive process. Such reduction was not even more dramatic because of the still limited possibilities this company has to explore its value chain relations.

Key words: Cost strategic management. Competitive criteria. Trade-off.

\section{INTRODUÇÃO}

A missão da gestão estratégica de custos, no âmbito empresarial, cresce à medida que evoluem as exigências dos consumidores e o acirramento da concorrência entre as empresas. Os empreendimentos que objetivam subsistir e crescer em um mercado cada vez mais disputado precisam desenvolver vantagem competitiva em sua atuação.

Uma das alternativas é se criar diferenciais em produtos e serviços e manter preços competitivos em relação à concorrência. Isso pode ser materializado pela diversificação de produtos e pela flexibilidade operacional, visando possibilitar rápidas respostas às novas exigências de mercado. O foco na gestão estratégica de custos pode contribuir para viabilizar o sucesso dessa forma de atuação.

Ter flexibilidade, em uma produção diferenciada pela customização, conduz a um conflito com a ocorrência de custos crescentes. Dessa forma, o presente estudo foi desenvolvido com o objetivo de responder ao seguinte problema de pesquisa: como a gestão estratégica de custos pode atuar para minimizar o trade-off entre custos e flexibilidade? Para respondê-lo tem-se a união dos conceitos derivados da administração estratégica de operações com os originados da gestão estratégica de custos. 
A gestão estratégica de custos como instrumento para redução do trade-off entre custo e diferenciação baseada na flexibilidade César Volnei Mauss, Juliano Machado de Magalhães, Marcos Antonio de Souza

Em seu âmbito mais específico, o estudo procurou analisar como a gestão estratégica de custos pode atuar para reduzir os custos operacionais incrementados pela adoção da estratégia de diferenciação dos produtos através da customização sob medida; trata-se, portanto, da ocorrência do trade-off entre custo e flexibilidade.

Para subsidiar o desenvolvimento do trabalho, analisa-se a estrutura do tradeoff (custos versus flexibilidade) focado à área de operações da empresa objeto de estudo para, posteriormente, realizar o confronto dos aspectos empíricos apurados com a teoria que trata dessa temática. Espera-se, com isso, determinar até onde a gestão estratégica de custos pode atuar para manter o equilíbrio entre custos e a diferenciação.

Busca-se, também, mensurar como a adoção de uma estratégia de customização podel levar à redução de custos no futuro. Por fim, a pesquisa também apura como a gestão estratégica de custos pode utilizar-se da logística e das relações de fornecimento como fatores críticos para a obtenção de vantagem competitiva para a empresa, possibilitando minimizar o referido trade-off.

\section{REFERENCIAL TEÓRICO}

\subsection{Critérios Competitivos}

Os critérios competitivos foram propostos por Wheelwright (1984) para orientar a estratégia a ser seguida pela área de operações, convergindo com os trabalhos de Skinner (1969, 1974), que iniciou pesquisas colocando o papel das operações como ponto de diferenciação para a estratégia da empresa. Dessa forma a compreensão dos critérios competitivos pode proporcionar o entendimento dos possíveis reflexos nas decisões estratégicas da empresa. Paiva et al., (2004) esclarecem que critérios competitivos compreendem um conjunto de prioridades que a empresa elege para competir no mercado.

Para Hill (1985) existem dois tipos de critérios: os qualificadores e os ganhadores de pedidos. Enquanto que o primeiro é básico para que o produto possa ser aceito pelo mercado, o segundo proporciona diferenciação para o produto em relação à 
A gestão estratégica de custos como instrumento para redução do trade-off entre custo e diferenciação baseada na flexibilidade

César Volnei Mauss, Juliano Machado de Magalhães, Marcos Antonio de Souza

concorrência. Ambos visam possibilitar maior competitividade e consequente ganho de mercado. A decisão estratégica da empresa em optar por critérios somente qualificadores ou agregar os ganhadores de pedidos, é uma decisão que depende do tipo de mercado e da estratégia dos concorrentes.

De forma mais analítica, Wheelwright (1984) propôs os seguintes critérios: custo, qualidade, confiabilidade e flexibilidade. Posteriormente, outros autores utilizaram estes critérios como base para suas pesquisas, tais como New (1992), Noble (1995), Slack et al., (1999), Verma e Thompson (1999).

$\mathrm{Na}$ sequência são analisados os critérios competitivos: custos e flexibilidade, para explicar a sua relação com o trade-off e a forma como a gestão estratégica de custos pode agir neste âmbito.

\subsection{Trade-offs}

O trade-off pode ser caracterizado pela incompatibilidade entre dois ou mais critérios competitivos, onde a melhoria de um pode implicar negativamente em outro (Paiva et al., 2004). Este conceito teve suas raízes no trabalho realizado por Skinner (1969), que já chamava a atenção acerca da contribuição do setor produtivo para a formação da estratégia das empresas.

Os trade-offs estão sendo estudados por acadêmicos desde a década de 1960, tendo início com Skinner (1969 e 1974), e sendo seguido, posteriormente, por Corbett e Wasenhove (1993), Hayes e Pisano (1996), Silveira e Slack (2001), Boyer e Lewis (2002) e Teng e Cummings (2002). Tais estudos concluem sobre a necessidade da empresa escolher critérios competitivos consistentes para sustentar a sua estratégia genérica.

Neste contexto, para Wheelwright (1984) alguns destes critérios são considerados incompatíveis entre si. Skinner (1974) afirma que uma firma não pode ter um bom desempenho simultâneo em mais de um critério devido às limitações de recursos. Assim, a seleção de um critério pode inviabilizar o sucesso de outro.

Tem-se, então, que essa relação acaba por provocar implicações diretas para as decisões de estrutura e infra-estrutura da área de operações (Teixeira, 2005), pois uma 
A gestão estratégica de custos como instrumento para redução do trade-off entre custo e diferenciação baseada na flexibilidade

César Volnei Mauss, Juliano Machado de Magalhães, Marcos Antonio de Souza

empresa não poderia decidir operar com estratégia de customização em massa (flexibilidade), conforme Pine et al., (1993), e ainda desejar ser uma empresa com vantagem em custo (Wheelwright, 1984), comprovando a existência do trade-off.

Entretanto, outros pesquisadores negam a existência do trade-off. Por exemplo: Ferdows e De Meyer (1990), Corbett e Wasenhove (1993) e Collins et al., (1998), que defendem o modelo acumulativo de competências denominado Cone de Areia. Ferdows e De Meyer (1990) e Teixeira (2005), pressupõem que os critérios competitivos estão relacionados entre si e, consequentemente, o desempenho de um afetaria simultaneamente os demais, propiciando um fluxo contínuo de melhorias. Essas melhorias elevariam o desempenho de mais de um critério gerando um efeito cascata, implicando na inexistência do trade-off.

Alguns trabalhos empíricos como de Silveira e Slack (2001) e de Boyer e Lewis (2002) identificam traços da teoria proposta pelo modelo do Cone de Areia. Silveira e Slack (2001) visualizam o trade-off como sendo um fenômeno mutante que pode, de acordo com o mercado onde a empresa está inserida, mudar constantemente. Isso ocorre pelo desejo dos consumidores por diferentes atributos nos produtos. Boyer e Lewis (2002) identificaram a necessidade da empresa se ajustar rapidamente às mudanças no mercado, modificando o projeto de seus produtos e oferecendo grande variedade para seus clientes, de forma a satisfazer e propiciar o crescimento dos seus negócios.

Estudos já realizados permitem afirmar que o conceito de trade-off não visa transparecer imutabilidade. Ao contrário, deve ser visto como focado em uma linha de produção que necessita de constante melhoria (Silveira e Slack, 2001).

A compreensão do conceito de trade-off engloba o equilíbrio entre os diversos critérios competitivos que os gestores necessitam utilizar no seu dia-a-dia. A importância e a sensibilidade de analisar os trade-offs conjuntamente, poderia formar uma base para se lidar e resolver os novos trade-offs que viessem a surgir.

\subsection{Custo}

Besanko et al., (2006), Porter (1989 e 1998) e Wheelwright (1984) afirmam que a 
A gestão estratégica de custos como instrumento para redução do trade-off entre custo e
diferenciação baseada na flexibilidade César Volnei Mauss, Juliano Machado de Magalhães, Marcos Antonio de Souza

análise do critério custo envolve a mão-de-obra, o maquinário, as instalações e a matéria-prima. Visam oferecer produtos a preços competitivos de acordo com os valores determinados pelo mercado.

Mapes et al., (1997) indicam que historicamente o custo tem sido tratado como um critério e um fator preponderante dentro das operações, deixando-se de lado o nível de serviços ou outros critérios competitivos. Porém, com o decorrer do tempo e com a evolução dos estudos, esta lacuna está sendo preenchida e tem modificado o foco dos acadêmicos e dos gestores nas empresas. Os demais atributos estão crescendo em importância em relação ao custo, apesar deste fator ainda ser considerado bastante relevante por consumidores no momento da decisão de compra.

Uma empresa que deseja valorizar este critério competitivo deve realizar uma completa análise da estrutura dos seus custos, visando reduzi-los ao máximo possível para proporcionar preços mais baixos para os produtos (Paiva et al., 2004).

Pires (1995) destaca que o baixo custo se sustenta em três pilares básicos: economias de escala, curva de experiência e produtividade. Para se obter um produto com baixo custo, estes pilares devem ser seguidos para sustentar a estratégia corporativa. Porém, além destes tipos de economia, focada somente em custos, ainda existe a economia de escopo, que busca custos decrescentes dentro de uma gama de produtos para obter uma direta e positiva flexibilidade e diferenciação de mercado.

\subsection{Flexibilidade: Produção em Massa x Customização em Massa}

Segundo Wheelwright (1984), a flexibilidade é suportada por dois aspectos: o volume de produção, relacionado à habilidade de se aumentar ou reduzir a quantidade produzida rapidamente; e a diversidade de produtos, ligada diretamente à customização, focada na produção de itens não padronizados.

A flexibilidade é base para uma empresa operar com uma produção customizada, que pode vir a ser um diferencial produtivo onde a conceituação de customização em massa sustenta a estratégia de diferenciação do produto e o critério competitivo flexibilidade.

Com base na produção flexível, a customização pode atingir um nível de 
A gestão estratégica de custos como instrumento para redução do trade-off entre custo e
diferenciação baseada na flexibilidade César Volnei Mauss, Juliano Machado de Magalhães, Marcos Antonio de Souza

produção bastante próximo em volume ao obtido pela produção em massa. Pine et al., (1993; 1995), Gilmour e Pine (1997) e Dertouzos et al., (1992) conceituam a customização em massa como sendo uma nova tendência de produção, focada em pedidos individuais, personalizados, voltados para mercados de grandes volumes, relacionando-se dessa forma diretamente com a flexibilidade.

A customização em massa e a produção em massa podem co-existir na mesma empresa e propiciar benefícios derivados da sinergia entre eles como: a redução de custos produtivos e a redução do tempo de produção e de entrega do produto, conforme Kotha (1995).

O construto vai além de flexibilidade ou da agilidade para a provisão de bens e serviços feitos sob encomenda para o mercado, pois propicia o desenvolvimento de processo com numerosas variações selecionadas pelo cliente gerando pequeno aumento de tempo de produção, entrega ou de custo, como pode ser visto no Quadro 1.

\begin{tabular}{|c|c|c|}
\hline & Produção em Massa & Customização em Massa \\
\hline Foco & $\begin{array}{l}\text { Eficiência através de estabilidade e } \\
\text { controle }\end{array}$ & $\begin{array}{l}\text { Variabilidade e personificação através } \\
\text { da flexibilidade e respostas rápidas, } \\
\text { com maior custo }\end{array}$ \\
\hline Meta & $\begin{array}{c}\text { Desenvolvimento, produção, } \\
\text { comercialização e entrega de } \\
\text { mercadorias e serviços a preços } \\
\text { baixos. }\end{array}$ & $\begin{array}{l}\text { Desenvolvimento, produção, } \\
\text { comercialização e entrega de } \\
\text { produtos e serviços com suficiente } \\
\text { variedade e personalização } \\
\text { atendendo a vontade de todos. }\end{array}$ \\
\hline $\begin{array}{c}\text { Características } \\
\text { Chave }\end{array}$ & $\begin{array}{c}\text { Demanda estável } \\
\text { Mercados grandes e homogêneos } \\
\text { Custos normalmente mais baixos, } \\
\text { qualidade consistente, produtos e } \\
\text { serviços padronizados. Ciclos de } \\
\text { vida e desenvolvimento de produtos } \\
\text { longos } \\
\text { Produção para estoque }\end{array}$ & $\begin{array}{l}\text { Mercados fragmentados, } \\
\text { menos estáveis. Nichos } \\
\text { heterogêneos } \\
\text { Custos mais elevados, alta } \\
\text { qualidade, produtos e serviços } \\
\text { personalizados. } \\
\text { Ciclos de vida e desenvolvimento de } \\
\text { produtos curto Produção puxada } \\
\text { pelas necessidades do cliente }\end{array}$ \\
\hline
\end{tabular}

Quadro 1: Comparativo entre produção em massa e customização em massa

Fonte: Elaborado com base em Ahlström e Westbrook (1999), Lampel e Mintzberg (1996) e Zipkin (2001)

Ahlström e Westbrook (1999), Lampel e Mintzberg (1996) e Zipkin (2001), 
A gestão estratégica de custos como instrumento para redução do trade-off entre custo e
diferenciação baseada na flexibilidade César Volnei Mauss, Juliano Machado de Magalhães, Marcos Antonio de Souza

apresentam algumas características marcantes da customização em massa: 1) cada cliente fornece uma informação única e o produto é fabricado para atender este requerimento; 2) os processos de produção são flexíveis; 3) inexistem estoques; 4) "built to order" ao invés de "built to inventory"; e 5) montagem "on demand" para cada cliente individual.

Não existe mais o cenário de uma melhor forma de gestão, pois o mercado e os clientes forçam a empresa a rapidamente mudar seus produtos e as formas de comercializá-lo, onde a clássica expressão "one best way" perdeu sua força perante as práticas gerenciais. Nesse contexto, mudanças de tecnologias de produtos e de processos suportam este cenário aliado ao aumento da competição entre empresas e novos entrantes globalizados (Porter, 1998). Além destas mudanças, as ações de marketing criam no consumidor a necessidade de possuir produtos cada vez mais exclusivos, característica mais clara em consumidores de maior poder aquisitivo (Ahlström e Westbrook, 1999; Lampel e Mintzberg, 1996; Zipkin, 2001).

Como consequência tem-se a geração de pequenas alterações no tempo de produção e, consequentemente, no seu custo, os quais podem ser reduzidos gradativamente pela curva de experiência (Besanko et al., 2006).

Visando obter os benefícios da customização, os gestores possuem desafios a serem vencidos como: produzir com tempo de entrega compatível ao da produção em massa e desenvolver processos flexíveis para suportar a diversificação. São três os pontos-chave para se atingir estas mudanças: o primeiro é a curva de experiência já citada; o segundo ponto corresponde ao modelo acumulativo de competências denominado Cone de Areia (Ferdows e Meyer,1990); e, no terceiro, ainda haveria a influência do pacote tecnológico a ser embarcado, com foco na ampliação da produtividade da empresa, segundo Ahlström e Westbrook (1999).

Pela contextualização realizada e definições apresentadas anteriormente, cabe destacar que empresas podem obter resultados acima da média, combinando atributos como custos e flexibilidade alocados aos produtos/serviços comercializados, sem comprometer os resultados financeiros ou tendo que se posicionar no "meio termo" de Porter (1989). Para tanto, a empresa precisa utilizar a gestão estratégica de custos para 
A gestão estratégica de custos como instrumento para redução do trade-off entre custo e diferenciação baseada na flexibilidade

César Volnei Mauss, Juliano Machado de Magalhães, Marcos Antonio de Souza

rever aspectos gerenciais e criar estratégias para aproveitar oportunidades de redução de custos e de flexibilidade, pela análise das atividades na cadeia de valor e pela utilização da logística integrada, como descrito a seguir.

\subsection{A Gestão Estratégica de Custos}

Com as novas visões técnicas de gestão e a crescente competitividade do mercado globalizado, a contabilidade de custos também teve que focar-se na estratégia empresarial, dando surgimento à contabilidade estratégica de custos (Ott, 2004). autor assinala que o seu surgimento ocorreu através dos trabalhos de Shank (1989) e Shank e Govindarajan (1997), e visa orientar as empresas dentro de um ambiente extremamente competitivo e diferente da realidade das décadas anteriores a 1980, onde à competição baseava-se unicamente em custos.

Essa nova visão surgiu porque as empresas precisaram ampliar os seus horizontes de competição, onde o custo passou a ser um qualificador e os demais critérios competitivos como a qualidade, flexibilidade e desempenho passaram a ser um diferencial no mercado.

Dessa forma, a gestão estratégica de custos possui uma postura pró-ativa focada no processo de gestão empresarial, e idealizadora de um sistema de informação contábil que tem por finalidade dar amparo às decisões estratégicas dos gestores. Assim, Shank e Govindarajan (1997) destacam que a informação contábil é utilizada na formulação, comunicação, desenvolvimento e na implementação das estratégias empresariais e, posteriormente, na sua avaliação e controle.

Ainda, segundo esses autores, a gestão estratégica de custos relaciona-se a três temas chaves: a análise do posicionamento estratégico da empresa, a análise dos determinantes de custo e a análise da cadeia de valor.

A análise do posicionamento estratégico visa à compreensão da posição de rentabilidade dentro do conjunto do mercado que, de acordo com Porter (1989), é a base fundamental para o desempenho acima da média no longo prazo e para se obter e manter a vantagem competitiva.

$\mathrm{Na}$ análise dos determinantes de custos, Machado (2002) destaca que o objetivo 
A gestão estratégica de custos como instrumento para redução do trade-off entre custo e diferenciação baseada na flexibilidade

César Volnei Mauss, Juliano Machado de Magalhães, Marcos Antonio de Souza

não é analisar a relação de causa e efeito imediatos entre o custo da produção e o volume produzido. Observar apenas o relacionamento dos custos com o volume produzido é perder a riqueza da análise do comportamento dos custos. Portanto, os determinantes de custos devem ser procurados nas decisões que envolvem a estrutura (escala, escopo, experiência, tecnologia e complexidade) e as habilidades operacionais da empresa. Isso é relevante porque os determinantes tratam de aspectos que antecedem o início da produção e influenciam as condições e formas de organizar a produção, as quais se inter-relacionam de forma complexa.

A utilização da análise da cadeia de valor, segundo Nakagawa (1993) e Ott (2004), traz como vantagens a eliminação das atividades que não agregam valor dentro de toda a cadeia e a redução dos custos a partir do seu acompanhamento contínuo através de relatórios de gestão e da análise dos determinantes de custos.

\subsection{A análise da cadeia de valor e logística como instrumentos para reduzir o trade-off}

A importância da gestão estratégica de custos cresce à medida que cresce também a importância da adoção, pelas empresas, de mais de um critério competitivo. Neste sentido, Silveira e Slack (2001) destacam que o conceito de trade-off na manufatura também teve sua importância exaltada nos últimos anos e passou a fundamentar a estratégia industrial, exigindo que as empresas evoluíssem de uma estratégia baseada apenas em custos e produtividade, para integrar múltiplos objetivos como: qualidade, flexibilidade e variedade.

Saber que os trade-offs surgem da percepção do cliente que exige produtos a custos baixos e com certa diferenciação passa a exigir que os gestores de operações criem estratégias e reestruturem as operações para atender as novas necessidades e expectativas desses clientes. Portanto, entende-se que o trade-off repercute em toda a cadeia de valor da empresa, visto que esta exigência passa a ser cobrada também dos fornecedores que, por sua vez, cobram dos seus fornecedores e assim sucessivamente. Ou seja, o trade-off é repassado para os operadores logísticos que recebem o encargo de atuar para minimizar o problema do seu cliente e ainda manter o nível de serviço ofertado a um custo acessível (Lima, 2002). 

A gestão estratégica de custos como instrumento para redução do trade-off entre custo e
diferenciação baseada na flexibilidade

César Volnei Mauss, Juliano Machado de Magalhães, Marcos Antonio de Souza

A gestão estratégica de custos pode atuar, de acordo com Shank e Govindarajan (1997), na compreensão de como as atividades de valor da empresa se encaixam nas cadeias de valor dos fornecedores e dos clientes. Ao se compreender como estas atividades estão dispostas dentro da cadeia de valor, se terá a compreensão de como são compostos os custos e a fonte de diferenciação dos produtos em relação aos concorrentes. Tendo essa compreensão, a empresa pode fixar metas de melhoria de desempenho pela redução de custos e ganho de diferenciação com a reformulação dessas atividades estratégicas dentro da cadeia de valor, analisando quatro áreas fundamentais: as ligações entre fornecedores; entre clientes; os processos internos e ligações através da cadeia de valor das unidades dentro da organização.

Ao estudar as ligações com os fornecedores e com os clientes a empresa deverá identificar quais são as atividades relevantes entre ambos e onde pode ser obtido benefício de negociação. Ao encontrar atividades sem valor para a empresa, mas que se encaixam na cadeia de valor do fornecedor ou cliente, deve-se transferi-las ao fornecedor ou ao cliente que poderá, com isso, agregar valor para si por meio da especialização e desenvolvimento de ferramental e habilidades para execução de tais atividades.

Souza et al., (2003) confirmam que essa integração entre fornecedores e clientes no processo operacional tirou a nitidez dos limites das organizações que eram totalmente independentes, para o surgimento de redes de empresas totalmente integradas e interdependentes. Porém, a pesquisa dos autores aponta para a falta de sincronia entre os desejos dos clientes e as práticas gerenciais da cadeia de suprimentos. Enquanto as empresas buscam fornecedores com menor custo, os clientes desejam melhor qualidade de produto. Segundo esses autores, fica evidente que a gestão da cadeia de suprimentos pode ser usada como uma ferramenta eficaz no balanceamento das necessidades da demanda e da capacidade do processo produtivo de forma a atingir a eficiência operacional em relação a custos, lead times e serviços aos clientes.

Um exemplo da atuação da gestão estratégica de custos na análise da cadeia é apresentado por Freitas e Pamplona (1999). Os autores propõem que se transfira para 
A gestão estratégica de custos como instrumento para redução do trade-off entre custo e diferenciação baseada na flexibilidade César Volnei Mauss, Juliano Machado de Magalhães, Marcos Antonio de Souza

as indústrias siderúrgicas a responsabilidade pelo reaproveitamento das sobras do aço vendido pelos seus distribuidores. Estes atualmente fornecem o aço já cortado e nas dimensões especificadas pelas construtoras, visando minimizar custos e desperdícios que ocorriam nos canteiros de obra, isto porque retalhos de aço para uma construtora são considerados entulhos e para as siderúrgicas matérias-prima. Os autores destacam que tais ligações devem adicionar benefícios mútuos e serem melhor exploradas pela análise da cadeia de valor, para identificar onde as suas atividades de valor poderiam criar benefícios ao cliente, fornecedor e vice-versa.

Com a nova configuração da execução das atividades depois da intervenção na cadeia de valor, tanto para o distribuidor como para a empresa, que repassa a responsabilidade da realização de grande parte das atividades para o distribuidor, ocorrerá a redução do tempo de entregas, redução dos erros e desperdícios corriqueiros que ocorreriam nas etapas transferidas.

Tal estratégia operacional já é adotada há anos pelas montadoras de automóveis para eliminação do trade-off. Lacerda (2004), por meio da análise das corecompetences de Hammel e Prahalad (1990), indica que foram transferidos para os fornecedores mais capacitados tecnologicamente a responsabilidade pelo fornecimento de módulos inteiros dos veículos e ainda foram estabelecidas relações de fornecimento integradas entre as empresas, visando o ganho de flexibilidade da produção e redução de custos. A autora destaca que a competição não ocorre somente entre as empresas, mas também entre as cadeias, sempre buscando a redução de custos e a diferenciação para o ganho de competitividade; e, para isso, é necessária a integração em uma cadeia de fornecimento que tenha o foco nas atividades que mais agregam valor.

Lacerda (2004, p. 10) enfatiza que "na indústria automotiva, a modularidade tem sido usada como elemento viabilizador dessa atuação combinada das firmas de modo a atender a demanda por flexibilidade". Destaca, ainda, que as relações de fornecimento modulares possuem um tempo de resposta inferior às não modulares e permitem maiores variações (flexibilidade) em sua produção sem incorrer em custos adicionais ou perda de performance.

Portanto, a montadora evita o trade-off pelo uso da logística integrada, pois 
A gestão estratégica de custos como instrumento para redução do trade-off entre custo e diferenciação baseada na flexibilidade

César Volnei Mauss, Juliano Machado de Magalhães, Marcos Antonio de Souza

repassa ao fornecedor a responsabilidade de também se flexibilizar e absorver as variações nas necessidades dos consumidores, ou seja, a integração já ocorre desde o desenvolvimento dos produtos, passa pela gestão operacional que deve observar toda a cadeia produtiva e desemboca no pós-venda, onde é obtido o feedback de todo processo. Nesse ponto é confirmada a teoria proposta por Lima (2002) de que os operadores logísticos recebem a transferência do trade-off e a responsabilidade de auxiliar os clientes a minimizá-los.

Com esta visão, deve-se ter em mãos uma ferramenta eficaz de avaliação dos fornecedores e de mensuração dos custos totais de fornecimento, como descrito a seguir.

\subsection{Total Cost of Ownership (TCO)}

Um dos instrumentos mais relevantes que surgiram como forma de gerar informação de custos e dar amparo às decisões diárias é o TCO, também denominado como Custo Total de Uso e Propriedade. O TCO considera que na decisão de compra de determinado produto devem ser acrescidos ao preço de aquisição todos os gastos efetivados e esperados em todas as atividades que ocorrem antes, durante e depois do ato de aquisição, inclusive os custos de manutenção e descarte, avaliados a valor presente (Freires, 2000; Alves e Cardoso, 2005).

O TCO oferece uma visão de economia de custos no longo prazo, quando os gastos são mais relevantes do que o custo de aquisição do produto em curto prazo, unicamente. Dessa forma, mesmo que no curto prazo os custos unitários aumentem em decorrência de investimentos em diferenciação, no longo prazo pode haver um aumento do volume de vendas devido à contribuição da diferenciação para o aumento da demanda, o que fará com que os custos unitários voltem a cair; consequentemente, haverá o retorno à posição de baixo custo (Ribeiro et al., 2004).

Assim, com as técnicas do TCO integradas à gestão estratégica de custos, podese comprovar a inexistência do trade-off em longo prazo, ao se afirmar que um produto customizado tem o seu custo de propriedade total reduzido para o cliente no longo prazo, pois atenderá de uma forma mais completa as suas necessidades. Isso ocorre 
A gestão estratégica de custos como instrumento para redução do trade-off entre custo e diferenciação baseada na flexibilidade

César Volnei Mauss, Juliano Machado de Magalhães, Marcos Antonio de Souza

porque ele foi adquirido de forma projetada, considerando todas as suas exigências, o que Ihe trará um tempo de vida útil maior, tanto em termos de durabilidade quanto de utilidade e desempenho.

A segunda contribuição do TCO para a redução de custos ocorre com a sua integração à gestão estratégica de custos para subsidiar a tomada de decisão empresarial na seleção de fornecedores de forma a minimizar os trade-offs. Dado que a logística integrada é um fator crítico para a redução do trade-off, é necessário um instrumento que possibilite a avaliação criteriosa do desempenho e do custo total de cada fornecedor da empresa.

De acordo com Ellram (1995), o TCO surgiu para se custear e avaliar uma parcela específica da cadeia de suprimentos (o fornecedor), que possui um papel crucial na obtenção de vantagem competitiva, tanto em custos como em diferenciação. Destaca, ainda, que os sistemas de contabilidade comumente utilizados somente orientam o processo decisório de compra com base no preço cotado do produto e ignoram outros gastos relevantes associados tanto à transação com o fornecedor como aos custos operacionais decorrentes do uso do bem.

Freires (2000) apresenta um sistema de avaliação que considera custos e despesas diversas, inclusive relativo à correção de falhas no fornecimento, tais como: deficiências de entrega, burocracia, re-trabalho, devoluções por não conformidade, etc. Tais gastos devem ser mensurados e devem integrar os gastos de não conformidade e devem ser somados ao preço de compra, para se apurar o gasto total de aquisição do produto. Estes gastos totais divididos pelo preço de compra possibilitam identificar o Índice de Desempenho de Fornecedor (IDF). A representação matemática é a seguinte:

IDF = gastos de não conformidade + preço de compra preço de compra

Com o IDF é possível criar, sob a ótica do TCO, um ranking de desempenho dos fornecedores, identificando quais são os mais eficientes e que serão privilegiados 
A gestão estratégica de custos como instrumento para redução do trade-off entre custo e diferenciação baseada na flexibilidade

César Volnei Mauss, Juliano Machado de Magalhães, Marcos Antonio de Souza

quando da decisão sobre a aquisição.

Por fim, utilizando-se dos aspectos elencados neste artigo para a análise do trade-off proposto, o TCO passa a ser um dos instrumentos que traz o suporte decisório necessário para a seleção de fornecedores e o estabelecimento de indicadores para avaliação do seu desempenho. Com sua análise, direciona os gestores para uma possível mudança nos processos operacionais, visto que identifica onde os fornecedores devem focalizar seus esforços para melhoria da cadeia produtiva e onde estão as oportunidades de reestruturação dos processos e dos possíveis cortes de custos.

\section{ASPECTOS METODOLÓGICOS}

No desenvolvimento da pesquisa adotou-se a estratégia metodológica de estudo de caso único, objetivando confrontar aspectos teóricos com a realidade observada na empresa objeto de estudo. Autores como Silveira e Slack (2001) e Teng e Cummings (2002) também realizaram estudos com metodologia semelhante. O estudo foi desenvolvido durante o período de 11/12/2005 a 14/03/2006.

Também foi analisada a utilização e a contribuição da gestão estratégica de custos, com suas técnicas de análise da cadeia logística e de valor da empresa, visando identificar se houve redução do trade-off, tanto no âmbito de uma linha de produção padronizada, como em outra customizada.

Complementando, também foram analisadas e mensuradas as alterações realizadas na estrutura operacional quando da conversão da produção padronizada para customizada.

Como amostra do estudo utilizou-se a Indústria de Móveis Finger Ltda, empresa localizada no município de Sarandi, RS. A empresa iniciou sua história no final da década de 1970 com a produção de cabos para enxadas, foices e machados, além de brinquedos para crianças, fabricados de forma artesanal. Com o tempo, o leque de produtos foi ampliado para aberturas, portas, dormitórios, cozinhas, estantes e móveis para banheiro, todos fabricados sob encomenda de acordo com a necessidade do 


\section{A gestão estratégica de custos como instrumento para redução do trade-off entre custo e diferenciação baseada na flexibilidade}

César Volnei Mauss, Juliano Machado de Magalhães, Marcos Antonio de Souza

cliente.

Em 1992 a empresa passou a produzir somente móveis em série (roupeiros, cômodas e cozinhas) com vendas exclusivamente para lojas. Em 1998 a Finger mudou seu foco de produção e entrou em um nicho mais específico de mercado: a produção de cozinhas, dormitórios e salas de estar customizadas, para atingir uma produção de 16.000 módulos/mês, vendidos no Brasil e nos Estados Unidos.

Atualmente, com 80 colaboradores a empresa produz 15 modelos de cozinhas, com mais de 150 opções de módulos para composição de projetos desenvolvidos através do software PROMOB 4i, disponibilizado em aproximadamente 250 pontos de venda.

A coleta dos dados ocorreu por meio de entrevista semi-estruturada com os gestores da empresa e pelo exame de documentos disponibilizados para análise dos custos operacionais e das alterações efetuadas a partir da adoção da customização iniciada em 1998. A operacionalização da pesquisa ocorreu com base nos aspectos teóricos analisados na revisão da literatura. Foi desenvolvido um roteiro para a realização das entrevistas em profundidade, englobando os seguintes aspectos: TCO; comparação dos dados de custos dos produtos de 1998 com 2005; logística interna e externa; caracterização dos fornecedores; aspectos ligados ao PCP e as compras; inovação; critérios competitivos (desempenho de entrega, qualidade, custo, flexibilidade e confiabilidade); trade-off (aspectos teóricos e apresentação de exemplos para contextualizar); aspectos gerais do produto e da sua produção; sistema produtivo adotado atualmente e no passado; e principais linhas de produtos.

A coleta dos dados ocorreu por meio de entrevistas realizadas através de questionário pré- estruturado e pela troca de e-mails com o diretor e os responsáveis pelas linhas de produção, além do exame de documentos contábeis disponibilizados para identificação e análise dos custos operacionais e das alterações efetuadas quando da adoção da customização. Foram ainda analisados o potencial, utilização e contribuição da cadeia logística e de valor da empresa e suas contribuições para a redução do trade-off, tanto no âmbito de uma linha de produção padronizada, como em outra customizada. Foram mensuradas as alterações realizadas na estrutura 
A gestão estratégica de custos como instrumento para redução do trade-off entre custo e
diferenciação baseada na flexibilidade César Volnei Mauss, Juliano Machado de Magalhães, Marcos Antonio de Souza

operacional quando da conversão da produção padronizada para customizada.

\section{APRESENTAÇÃO DOS RESULTADOS}

\subsection{O Processo Operacional}

O processo operacional da Finger inicia com a venda realizada através de lojas conveniadas, ocasião em que é feito o projeto personalizado do produto desejado pelo cliente. Dessa forma, a produção da empresa é caracterizada, conforme Paiva et al., (2004) e Lampel e Mintzberg (1996), como de customização sob medida, sendo este processo demonstrado pela Figura 1.

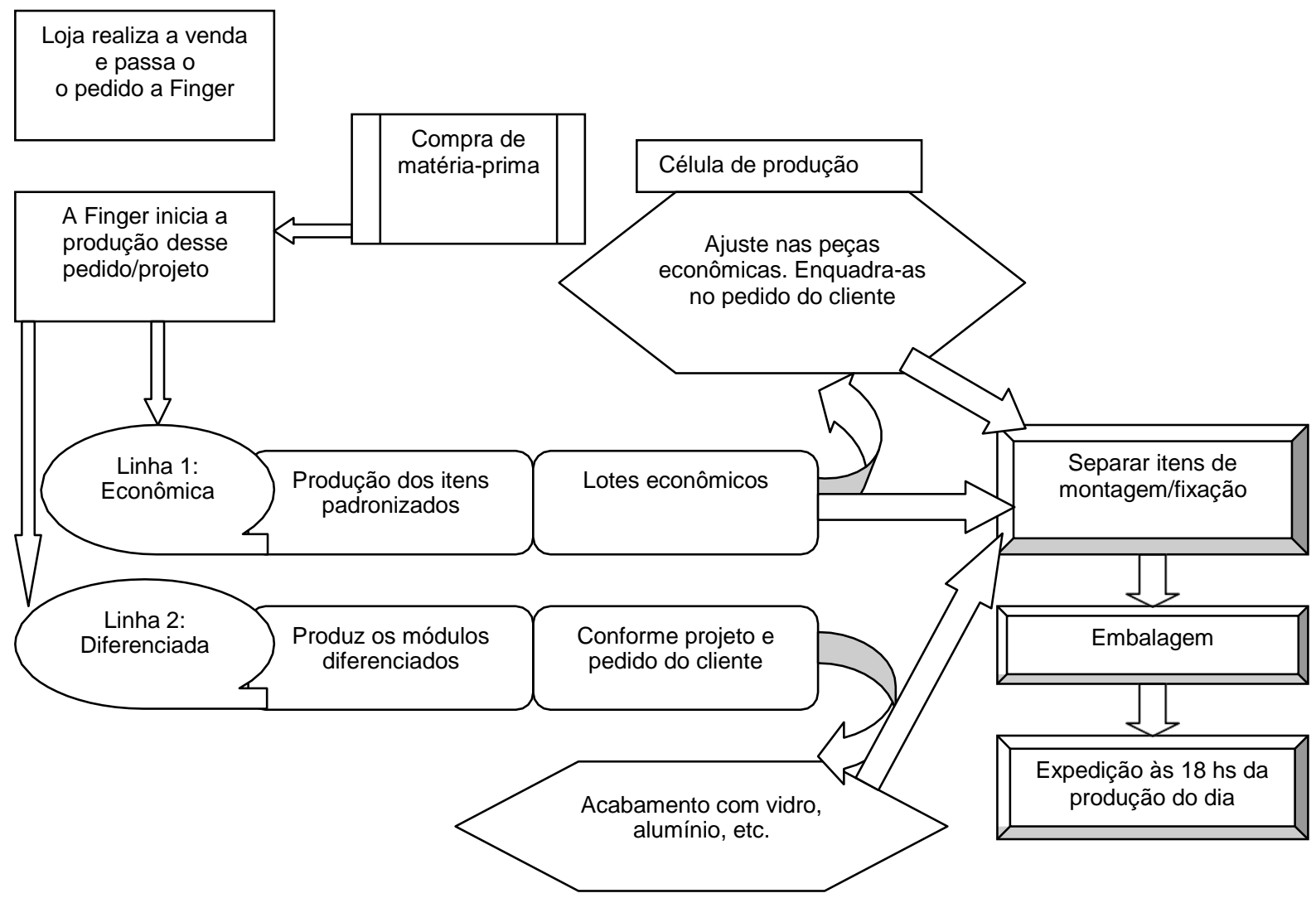

Figura 1 - llustração do processo operacional da Finger

Fonte: desenvolvida pelos autores 
A gestão estratégica de custos como instrumento para redução do trade-off entre custo e
diferenciação baseada na flexibilidade César Volnei Mauss, Juliano Machado de Magalhães, Marcos Antonio de Souza

Como é apresentado na Figura 1, o projeto é desenvolvido nas lojas pelo cliente com o auxílio de vendedores projetistas especialmente treinados pela Finger e profundos conhecedores de seus produtos, utilizando o software PROMOB. Posteriormente à efetivação do pedido, o sistema gera uma listagem constando todos os itens adquiridos e seus códigos, inclusive dos módulos fora do padrão adotado pela empresa, constando, neste caso, a configuração estabelecida pelo cliente. Tal listagem é encaminhada à fábrica.

Esses módulos sob medida caracterizam um outro diferencial dos produtos Finger e demonstram a sua flexibilidade operacional, possibilitando oferecer ao cliente um produto altamente customizado em relação às dimensões indicadas nos padrões iniciais.

A empresa organizou a sua operação de acordo com os critérios da customização em massa estabelecidos por Zipkin (2001), possuindo os três elementos principais indicados pelo autor. Através do software PROMOB e do projetista vendedor a empresa utiliza um processo de descoberta das informações, das necessidades e desejos dos consumidores. A tecnologia produtiva é adequada e possibilita o atendimento das especificações identificadas na etapa anterior pelo cliente. A logística, que atua em um processo subsequente, propicia o correto e tempestivo fechamento do pedido e a posterior entrega do mesmo, montado e em conformidade com as especificações.

De posse dos projetos o programador de produção estabelece o cronograma produtivo do dia por ordem de chegada dos pedidos e emite etiquetas com código de barras que identificam o produto e todas as características exigidas pelos clientes, bem como a loja que efetuou a venda e o comprador, organizando a produção por pedido de forma puxada.

Por esse motivo as operações são organizadas em etapas e em formato de linhas e células. Existem duas linhas principais: (a) a primeira congrega as atividades com produção padronizada, regidas por lotes econômicos; (b) a segunda opera com a diferenciação propriamente dita e produz os módulos com tamanhos diferenciados e de 
A gestão estratégica de custos como instrumento para redução do trade-off entre custo e
diferenciação baseada na flexibilidade César Volnei Mauss, Juliano Machado de Magalhães, Marcos Antonio de Souza

acordo com as especificações do cliente. O processo completo compreende quatro etapas complementares.

Tem-se então que a terceira etapa, no formato de célula, envolve os trabalhos de acabamento com vidro, alumínio e outros materiais especiais, complementando as duas anteriores. A quarta etapa, também uma célula de atividades complementares, realiza trabalhos de ajuste das peças produzidas nos lotes econômicos, visando enquadrá-las nas exigências especiais dos clientes em termos de tamanho e medidas de cada projeto. A quinta etapa engloba o processo de separação dos itens de fixação e montagem dos produtos. Por fim, a sexta etapa refere-se à embalagem dos produtos prontos e remessa para expedição.

A expedição somente recebe os produtos com todos os componentes prontos, agregados e controlados através da identificação pelo código de barras. Toda a produção do dia é normalmente embarcada à noite. Portanto, não existe estoque de produtos acabados, visto que o processo produtivo é puxado pela venda efetuada.

O transporte é realizado por empresas terceirizadas diretamente para o local indicado pelo consumidor, onde a montagem do produto é efetuada por pessoal treinado e agregado às lojas revendedoras. Neste momento é feita a última conferência das especificações dos produtos que constam no projeto. Se houver divergência ou problemas em alguma peça, a mesma é prontamente substituída pela Finger.

Ressalta-se que a análise do processo de compra está sendo realizada em separado devido ao fato de não ocorrer de forma puxada, pois é realizado de forma "empurrada" sem observar a necessidade oriunda dos pedidos de compra como ocorre com o restante das operações da empresa. Tal fato ocorre dessa forma devido a Finger estar localizada fora do pólo moveleiro gaúcho.

Assim, não é possível implantar uma estratégia just-in-time para a compra de matéria-prima, nem uma estratégia de fornecimento modular ou de condomínio. Portanto, nesse aspecto não é possível estabelecer relações de fornecimento integradas nem a gestão de produção coordenada entre as empresas visando o ganho de flexibilidade da produção, redução de custos e melhoria da performance, conforme indicado por Lacerda (2004). 
A gestão estratégica de custos como instrumento para redução do trade-off entre custo e diferenciação baseada na flexibilidade

César Volnei Mauss, Juliano Machado de Magalhães, Marcos Antonio de Souza

As compras de matéria-prima são realizadas para manutenção de um estoque suficiente para atender a demanda de 20 dias, devido à distância da empresa dos seus principais fornecedores, os quais não realizam entregas com prazos menores. Atualmente, apenas o fornecedor de aramados entrega o seu produto na lógica do justin-time e em módulos prontos para serem agregados aos móveis de cozinha já na fase de expedição do produto, conforme preceituado por Shank e Govindarajan (1997).

\subsection{A análise do trade-off}

Ao analisar o processo produtivo da Finger chega-se à conclusão de que não há diferença operacional significativa de uma linha de produtos standard para uma linha de produtos diferenciados. A infra-estrutura é a mesma, sem a necessidade de qualquer alteração em termos de tecnologia, matéria-prima, equipamento ou instalações físicas.

A diferença está, basicamente, no tempo de produção da segunda linha operacional (diferenciada), onde a matéria-prima é trabalhada de forma individualizada, demandando maior tempo e atenção na produção e mais set-ups no maquinário. Por exemplo, na primeira linha (por lotes econômicos) as máquinas cortam o total de sua capacidade (4 chapas de MDF por vez), enquanto que na linha diferenciada o corte ocorre com uma chapa por vez.

Outra diferença consta na quarta etapa de produção, onde são realizados os ajustes de tamanho das peças oriundas dos lotes econômicos, conforme já descrito no tópico 4.1.

Também ocorreram aumentos nas despesas de comercialização devido à necessidade de acompanhar de forma mais próxima o processo de venda. Por isso é realizado o constante treinamento dos projetistas e vendedores, assim como atualização do software utilizado para elaboração dos projetos por meio da incorporação de novos recursos.

Quanto aos critérios competitivos, a estratégia de diferenciação da empresa engloba:

a) Qualidade nos produtos: oferecendo além da matéria-prima básica (MDF e 
A gestão estratégica de custos como instrumento para redução do trade-off entre custo e diferenciação baseada na flexibilidade César Volnei Mauss, Juliano Machado de Magalhães, Marcos Antonio de Souza

aglomerado) outros materiais mais nobres (alumínio e acrilato) para propiciar uma melhor estética e valorização do bem. Conforme destacado por Paiva et al.,(2004), esse procedimento possibilita uma performance igual ou superior a dos concorrentes diretos Todeschini Italinea que pertence ao grupo Todeschini, considerada a principal rival no mercado; Criare da Carraro; Favorita e Bentech, que concorre por menor custo, porém com qualidade inferior. Quanto às características secundárias a empresa oferece uma ampla variedade de itens que podem ser agregados ao produto de acordo com os desejos do cliente, buscando satisfação adicional, facilidade de uso, comodidade e observando a estética em geral. A empresa tem por regra que o produto deve tornar perceptível a durabilidade, confiabilidade e conformidade com o projeto elaborado no ato da venda. Os serviços agregados caracterizam-se pelo projeto customizado inicial e a montagem in loco do produto pronto.

b) Flexibilidade operacional: materializa-se conforme descrito no tópico anterior. A empresa oferece produtos passíveis de serem customizados em massa, conforme Paiva et al., (2004) e Wheelwright (1984). Também, cabe destacar o baixo tempo de resposta da empresa às novas exigências dos clientes, situado em aproximadamente três meses para mudança de linha, englobando: novas matérias-primas; alteração do mix de produtos pela inclusão de novas modelagens; oscilação do volume de produção de acordo com a demanda.

c) Desempenho de entrega: a empresa almeja possuir desempenho superior aos concorrentes diretos, realizando a entrega e montagem do produto em prazo sempre inferior ao estabelecido na venda, revisando a conformidade e corrigindo possíveis falhas do projeto no momento da montagem de forma instantânea, conforme descrito por Skinner (1969). A meta é expedir o produto em até 10 dias após a entrada do pedido; porém, em situações especiais, possui capacidade para expedição, em até três dias.

d) Inovação: é buscada através da utilização dos conhecimentos de um grupo de 
A gestão estratégica de custos como instrumento para redução do trade-off entre custo e diferenciação baseada na flexibilidade César Volnei Mauss, Juliano Machado de Magalhães, Marcos Antonio de Souza

engenheiros e dos próprios proprietários que buscam inspiração em viagens para outros países como a Itália e EUA, e da participação efetiva em feiras nacionais e internacionais. Visa inovar e qualificar sua linha de produtos e processos, conforme Paiva et al., (2004); como exemplo, pode-se citar o desenvolvimento da linha de dormitórios para complementar a linha de produtos já existente.

e) Estratégia em custos: a empresa, através da curva de experiência apresentada por Besanko et al., (2006) e Paiva et al., (2004), está reduzindo seus custos gradativamente. Conforme também é afirmado por Ribeiro et al., (2004), o impacto imediato que a diferenciação causa é a elevação dos custos unitários. Contudo, o aumento do volume de vendas proporcionado pela diferenciação, no longo prazo, levará novamente ao baixo custo. Por exemplo, a empresa de 2004 para 2005 aumentou o seu volume de produção e vendas em $23 \%$, mas, mesmo assim, apresentou redução no quadro de pessoal na ordem de $10 \%$ e redução do tempo de produção. Isso caracteriza uma considerável queda nos custos em decorrência do ganho de produtividade provocado também pela acumulação de competências (também denominado modelo do cone de areia). Pode-se, portanto, inferir que os critérios competitivos estão relacionados entre si e que o desempenho de um afeta aos demais e cria uma melhoria contínua, que por sua vez eleva o desempenho geral e possibilita a redução de custos (Ferdows e de Meyer, 1990) utilização e a inovação nas relações de fornecimento permitem maiores variações nas operações sem incorrer em custos adicionais ou perda de performance.

Neste contexto, surge a necessidade premente de realizar avaliações formais dos fornecedores e a utilização dos conceitos subjacentes ao TCO, tanto em nível de decisões de aquisição de máquinas quanto no âmbito de analisar a viabilidade econômica de se adquirir produtos de um determinado fornecedor.

Para fundamentar tal afirmação pode-se utilizar o exemplo da Rhodia, citado por Machado (2005), que destaca a meta da empresa de reduzir em $50 \%$ o seu número de fornecedores a nível mundial (no Brasil redução de 88 para 35), objetivando facilitar o controle e melhorar a eficiência logística. Objetiva-se com isso diminuir o 
A gestão estratégica de custos como instrumento para redução do trade-off entre custo e diferenciação baseada na flexibilidade César Volnei Mauss, Juliano Machado de Magalhães, Marcos Antonio de Souza

ciclo de entrega e consequentemente reduzir o custo logístico, o que remete novamente para a assertiva de Lima (2002) que ressalta a necessidade de um serviço logístico diferenciado e com a responsabilidade de agregar valor ao produto da empresa.

\subsection{Indicadores Operacionais}

$\mathrm{Na}$ Tabela 1 constam as variações nos custos e despesas da empresa pela conversão estratégica.

Tabela 1 - Variação nos custos e despesas da empresa com base no faturamento mensal

\begin{tabular}{|c|c|c|c|c|}
\cline { 2 - 5 } \multicolumn{1}{c|}{} & $\begin{array}{c}\text { Produção } \\
\text { padrão }\end{array}$ & Produção Customizada & Ganho/Perda & Variação \\
\hline Giro do estoque & 25 dias & 20 dias & (5 dias) & \\
\hline Custo financeiro do estoque & $4.5 \%$ & $3.6 \%$ & $(0.90 \%)$ & $(0.90 \%)$ \\
\hline Custo operacional do estoque & $0.75 \%$ & $0.40 \%$ & $0.35 \%$ & $0.35 \%$ \\
\hline N $^{\circ}$ colaboradores na produção & 42 & 68 & 26 & \\
\hline \% do faturamento & $7.28 \%$ & $7.96 \%$ & $+0.68 \%$ & $+0.68 \%$ \\
\hline Custo e despesas fixas & $15 \%$ & $20 \%$ & $+5.00 \%$ & $+5.00 \%$ \\
\hline \% trade-off (aumento custo) & & & & $\mathbf{4 , 4 3 \%}$ \\
\hline
\end{tabular}

Fonte: Desenvolvida pelos autores

Quando a empresa produzia de forma padronizada, utilizava um estoque médio de 25 dias. Após a implantação da produção customizada passou a ter um estoque médio de matéria prima de 20 dias, o que the proporcionou uma economia de $20 \%$ no seu estoque total. Considerando o percentual do lucro líquido de $8 \%$ auferido pela empresa em 2005 como o custo de oportunidade desperdiçado em estoque, e que na conversão estratégica foi realocado para expansão das vendas, pode-se afirmar que houve um ganho de $0,90 \%$ na rentabilidade.

Em relação ao custo operacional e logístico dos estoques a economia auferida pela redução do seu volume em 5 dias representou $0,35 \%$ do faturamento total.

Por outro lado, a customização demandou aumento do número de colaboradores, devido ao maior tempo de produção e trabalho em cada peça produzida. 
A gestão estratégica de custos como instrumento para redução do trade-off entre custo e
diferenciação baseada na flexibilidade César Volnei Mauss, Juliano Machado de Magalhães, Marcos Antonio de Souza

Porém esse custo foi quase que todo amortizado pelo aumento do faturamento da empresa em $67 \%$, restando o impacto em apenas $0,68 \%$. Já os custos e despesas fixas sofreram um aumento de $5 \%$, motivado pela necessidade de maiores controles operacionais, tecnologia de venda, treinamento constante do pessoal e maior interação da indústria com os pontos de venda.

Dessa forma, é possível concluir que a conversão estratégica da Finger criou um trade-off na área de operações, mas que, com o decorrer do tempo já diminuiu e atualmente ainda apresenta um aumento dos custos em relação a produção padronizada na ordem de 4,43\% (5,00\%+0,68\%-0,90\%-0,35\%) do seu faturamento, que possivelmente caia mais ainda com a implementação das ferramentas sugeridas (TCO e a análise da cadeia de valor). Porém, tal incremento nos custos não eliminou o impacto positivo que a customização trouxe para os lucros da empresa que aumentaram $166 \%$, conforme pode ser visualizado na Tabela 2.

Tabela 2 - Comparação de informações operacionais da Finger

\begin{tabular}{|c|c|c|c|}
\cline { 2 - 4 } \multicolumn{1}{c|}{} & Produção padrão & Produção Customizada & Aumento/Redução \% \\
\hline Custo variável sobre o faturamento & $82 \%$ & $72 \%$ & $-12,20 \%$ \\
\hline Lucro líquido sobre o faturamento & $3 \%$ & $8 \%$ & $166 \%$ \\
\hline Capacidade instalada & 7.500 & 20.000 & \\
\hline Produção em módulos & 5.500 & 16.000 & \\
\hline Utilização da capacidade instalada & $73 \%$ & $80 \%$ & $9 \%$ \\
\hline
\end{tabular}

Fonte: Desenvolvida pelos autores

A Tabela 2 também demonstra que os custos variáveis caíram em relação ao faturamento na conversão para customizada, em virtude da maior eficiência na utilização dos recursos, acarretando a redução dos desperdícios e eliminação do excesso de produção. A maior eficiência nas operações também impactou no melhor aproveitamento da capacidade instalada da empresa que aumentou em $9 \%$.

Nestes termos, o caso Finger confirma a afirmação de Ribeiro et al., (2004) que o efeito imediato da diferenciação causa a elevação dos custos unitários, porém é compensado com o aumento do volume de vendas proporcionado pela diferenciação. Essa transição estratégica viabilizará, no longo prazo, a existência de baixo custo, 
A gestão estratégica de custos como instrumento para redução do trade-off entre custo e diferenciação baseada na flexibilidade César Volnei Mauss, Juliano Machado de Magalhães, Marcos Antonio de Souza

como é a tendência que se verifica e como pode ser observado na Figura 2. 


\section{A gestão estratégica de custos como instrumento para redução do trade-off entre custo e diferenciação baseada na flexibilidade \\ César Volnei Mauss, Juliano Machado de Magalhães, Marcos Antonio de Souza}

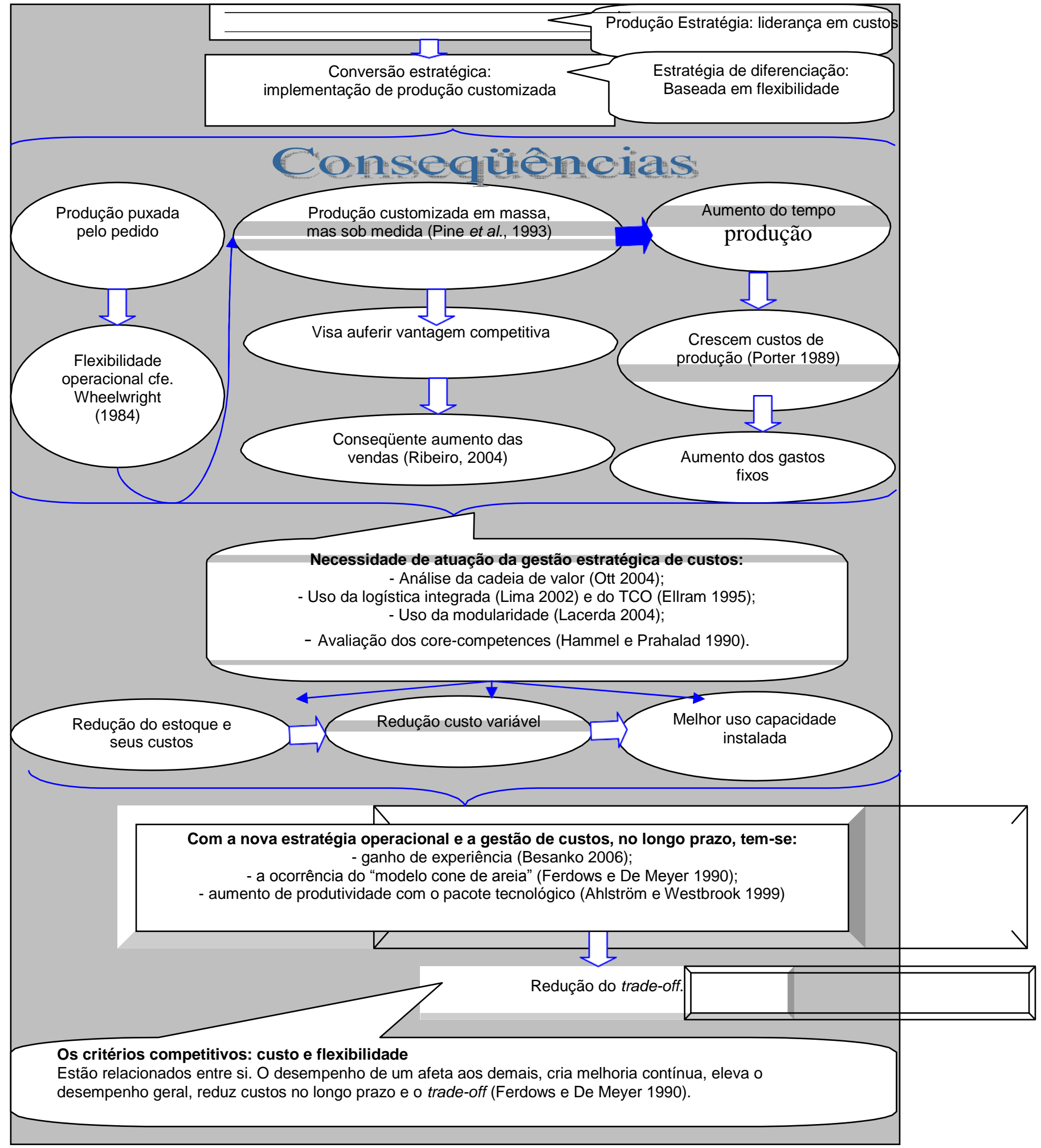

Figura 2 - Diagrama de Consequências e ganhos da conversão estratégica da Finger

Fonte: Desenvolvida pelos autores 


\section{A gestão estratégica de custos como instrumento para redução do trade-off entre custo e}

diferenciação baseada na flexibilidade

César Volnei Mauss, Juliano Machado de Magalhães, Marcos Antonio de Souza

Portanto, com a conversão estratégica, a empresa efetivamente passou a gerir melhor seus recursos e a obter ganhos com a customização em massa, cabendo, porém, reavaliar seu sistema de fornecimento para reduzir o número de fornecedores (atualmente em 50) e buscar a integração da única etapa operacional que ainda não é puxada pelo pedido do cliente, a compra. De fato, a eliminação total dos estoques representará uma redução de 3,58\% no custo (em relação ao faturamento), considerando o custo de oportunidade dos recursos. A utilização da gestão estratégica de custos para a análise dos core-competences e da logística integrada pode trazer como resultado final à empresa a liderança em custos no setor.

\section{CONSIDERAÇÕES FINAIS}

Este estudo confirma que o trade-off existe quando da conversão estratégica de uma empresa. Porém, com a evolução da curva de aprendizado, pelo modelo acumulativo de competências (cone de areia) e pelo aumento do faturamento motivado pelo crescimento das vendas (promovido com a utilização do marketing sobre a produção flexibilizada), o trade-off é amenizado e pode até vir a ser eliminado.

Também com a gestão estratégica de custos direcionando o uso da análise da cadeia de valor, dos determinantes de custos, da logística integrada e do TCO, é possível reduzir custos através da identificação e eliminação das atividades que não agregam valor nas operações da empresa. O resultado destas análises pode ser determinante para se atingir a eficiência operacional em relação à estratégia de diferenciação conjugada a preços baixos, área que para os gestores que se encontram em situação similar a identificada nesta pesquisa, sugere- se a correta análise do mercado no qual a empresa está inserida, o uso da análise da cadeia de valor, a utilização da logística integrada e do TCO objetivando criar um ambiente propício ao crescimento no nível competitivo da empresa em relação aos concorrentes. 


\section{REFERÊNCIAS}

AHLSTRÖM, P. e WESTBROOK, R. 1999. Implications of mass customization for operations management: an exploratory survey. International Journal of Operations and Production Management, 19(3):262-274.

ALVES, F.J. e CARDOSO, R.L. 2005. COQ e TCO: o impacto das decisões de qualidade no custo total de propriedade. Disponível em: http://www2.ueri.br/ faf/pastas prof/ricardo/industrial1. Acesso em: 25/06/2005.

BESANKO, D.; DRANOVE, D.; SHANLEY, M. e SCHAEFFER, S. 2006. A economia da estratégia. Porto Alegre, Bookman, 608 p.

BOYER, K. e LEWIS, M. 2002. Competitive priorities: investing the need for trade-offs in operations strategy. Production and Operations Management. 11(1):9-20.

COLLINS, R.S.; CORDON, C. e JULIEN, D. 1998. An empirical test of the rigid flexibility model. Journal of Operations Management, 16:133-146.

CORBETT, C. e WASSENHOVE, L. 1993. Trade-offs? What trade-offs? Competence and competitiveness in manufacturing strategy. California Management Review. 35(4):107122.

DERTOUZOS, M.L. 1992. Made in America: regaining the productive edge. Cambridge, Mass, MIT, $344 \mathrm{p}$.

ELLRAM, L.M. 1995. Total Cost of Ownership an analysis for purchasing. International Journal of Physical Distribution and Logistics Management. 25(8):4-23.

FERDOWS, K. e DE MEYER, A. 1990. Lasting improvements in manufacturing: in search of a new theory. Journal of Operations Management. 9(2):168-184.

FREIRES, F.M. 2000. Proposta de um modelo de gestão dos custos da Cadeia de Suprimentos. Dissertação Mestrado em Engenharia de Produção. UFSC, Florianópolis, $112 \mathrm{p}$.

FREITAS, D.T. e PAMPLONA, E.O. 1999. Uso da Cadeia de Valor para Definição das Atividades do PERT/COM. In: ENEGEP, 19, Rio de Janeiro, 1999. Anais... Rio de Janeiro. 1999.

GILMOUR, J.H. e PINE, B.J. II. 1997. The four faces of mass customization. Harvard Business Review. 75 (1): 91-101. 
A gestão estratégica de custos como instrumento para redução do trade-off entre custo e diferenciação baseada na flexibilidade César Volnei Mauss, Juliano Machado de Magalhães, Marcos Antonio de Souza

HAMMEL G. e PRAHALAD, C.K. 1990. The Core Competence of the corporation. Harvard Business Review, 68 (3): 79-91.

HAYES, R. e PISANO, G. 1996. Manufacturing strategy: at the intersection of two paradigm shifts. Production and Operations Management. 5 (1): p 25-41.

HILL, T. 1985. Manufacturing Strategy - The strategic management of the manufacturing function. Londres, Macmillian Busine. 99-109 p.

KOTHA, S. 1995. Mass customization: implementing the emerging paradigm for competitive advantage. Strategic Management Journal. 16:21-42.

LAMPEL, J. e MINZTBERG, H. 1996. Customizing customization. Sloan Management Review. 37:21-30

LACERDA, J.S. 2004. Modularidade e Flexibilidade de Manufatura: uma análise comparativa. In: ENANPAD, 28, Curitiba, 2004. Anais... Curitiba. 2004.

LIMA, M.P. 2002. Custos Logísticos - Uma visão gerencial. COPPEAD, UFRJ. Disponível em: www.coppead.ufri.br, acesso em 08/08/2002.

MACHADO, A.P. 2005. Rhodia inicia pelo Brasil a reformulação da logística. Gazeta Mercantil. Caderno C, 23 Maio, p. 5.

MACHADO, N. 2002. Sistema de Informação de Custo: Diretrizes para Integração ao Orçamento Público e à Contabilidade Governamental. Tese de Doutorado. Faculdade de Economia, Administração e Contabilidade, USP, 221 p.

MAPES, J., NEW, C. e SZWEJCZEWSKI, M. 1997. Performance trade-offs in manufacturing plants. International Journal of Operations \& Production Management. 17(10):1020-1033.

NAKAGAWA, M. 1993. Gestão Estratégica de Custos: Conceito, sistemas e implementação. São Paulo, Atlas, 112 p.

NEW, C. 1992. World-class manufacturing versus strategic trade-offs. International Journal of Operations and Production Management. 12(6):19-31.

NOBLE, M.A. 1995. Manufacturing strategy: testing the cumulative model in a multiple country context. Decision Sciences. 26(5):693-721.

OTT, E. 2004. Contabilidade Gerencial Estratégica: Inter-relacionamento da contabilidade financeira com a contabilidade gerencial. BASE - Revista de Administração e Contabilidade da Unisinos. 1(1):35-36. 
PAIVA, E.L., CARVALHO, J.M.Jr. e FENSTERSEIFER, J.A. 2004. Estratégia de produção e de operações. Porto Alegre, Bookman. $192 \mathrm{p}$.

PINE, B.J. II, PEPPERS, D. e ROGERS, M. 1995. Do you want to keep your customers forever? Harvard Business Review. 73(2):103-14.

PINE, B.J. II, VICTOR, B. e BOYNTON, A.C. 1993. Making mass customization work. Harvard Business Review. 71(5):108-19.

PIRES, S. 1995. Gestão estratégica da produção. Piracicaba, Ed. Unimep. 269 p.

PORTER, M.E. 1989. Vantagem competitiva. 13ª ed., Rio de Janeiro, Campus. 512 p.

PORTER, M.E. 1998. Estratégia competitiva: técnicas para análise de indústrias e da concorrência. 16 ${ }^{\mathrm{a}}$ ed., Rio de Janeiro, Campus. 362 p.

RIBEIRO, F.C.F., PROENÇA, E.R; COELHO, F.P.; PISCOPO, M.R. e DE PAULA, S.L.C. 2004. O Dilema Custos versus Diferenciação: um Estudo de Caso na Companhia Siderúrgica Nacional. In: ENANPAD, 28, Curitiba, 2004. Anais... Curitiba. 2004.

SILVEIRA, G.; SLACK, N. 2001. Exploring the trade-off concept. International Journal of Operations and Production Management. 21(7):949-964.

SKINNER, W. 1969. Manufacturing - The missing link in corporate strategy. Harvard Business Review. 47(3):5-14.

SKINNER, W. 1974. The focused factory. Harvard Business Review. 52(3):113-121.

SLACK, N. e BRANDÃO, A.B.1999. Administração da produção. São Paulo, Atlas, 526 p.

SOUZA, M.F.S., MOORI, R.G. e MARCONDES, R.C. 2003. Sincronização das Expectativas dos Clientes com a Prática dos Fornecedores Quanto a Custos, Confiabilidade e Qualidade. In: ENANPAD, 27, Atibaia, 2003. Anais... Atibaia. 2003.

Shank, J.K. 1989. Strategic Cost Management: New Wine or Just New Bottles ?. Journal of Management Accounting Review. 1:47-65.

SHANK, J.K. e GOVINDARAJAN, Vijay. 1997. A Revolução de Custos: como reinventar e redefinir sua estratégia de custos para vencer em mercados crescentemente competitivos. Rio de Janeiro, Editora Campus, 341 p.

TEIXEIRA, R. 2005. Trade-offs em Serviços Customizados e o Ponto de Vista do Cliente. In: ENANPAD, 29, Brasília, 2005. Anais... Brasília. 2005.

TENG, B. e CUMMINGS, J.L. 2002. Trade-offs in Managing Resources and Capabilities. 
A gestão estratégica de custos como instrumento para redução do trade-off entre custo e diferenciação baseada na flexibilidade

César Volnei Mauss, Juliano Machado de Magalhães, Marcos Antonio de Souza

Academy of Management Executive. 16(2):81-91.

VERMA, R. e THOMPSON, G.M. 1999. Managing service operations based on customer preferences. International Journal of Operations and Production Management. 19(9):891905.

WHEELWRIGHT, S.C. 1984. Manufacturing strategy: defining the missing link. Strategic Management Journal. 5(1):77-91.

ZIPKIN, P. 2001. The Limits of mass customization. Sloan Management Review. 42(3):8187.

Data de Submissão: 31/07/2007

Data de Aceite: 08/2007 